http://ejtr.vumk.eu

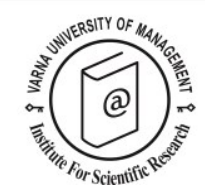

\title{
Family tourism: the importance of tourism for low-income families
}

\author{
Joana Lima ${ }^{1}$
}

Received: 25/05/2016

${ }^{1}$ GOVCOPP Research Unit \& Universidade de Évora, Departamento de Sociologia, Colégio do Espírito Santo, Largo dos Colegiais, 2, 7000-803 Évora, Portugal, Phone: + 351266740 805, E-mail: jisl@uevora.pt

\section{Supervisors: Celeste Eusébio Celeste Amorim Varum}

Institution awarding the Ph. D. Degree: University of Aveiro, Portugal

Date of defence: 01/06/2015

(c) 2017 Varna University of Management. All rights reserved

Citation: Lima, J. (2017) Family tourism: the importance of tourism for low-income families. Doctoral Dissertation Summary. European Journal of Tourism Research 15, pp. 167-170

\section{Goal and objectives of the dissertation Goal}

This thesis aims to extend the knowledge about the effects of family tourism, in general, and to low-income families, in particular. It should also contribute to find more effective and innovative ways of combating poverty and social exclusion, namely by highlighting the role of tourism as social innovation action.

\section{Objectives}

The thesis addresses the following research questions:

- What are the determinants of leisure and tourism expenditure among families with different income levels? Do low-income families have different leisure and tourism expenditure patterns compared to other families?

- What are the constraints to family tourism, and how important are financial constraints for family tourism?

- What are the effects of family tourism?

- Which are the determinants of these effects?
- Do low-income families have different effects from other families?

- Can tourism tackle social exclusion of low-income families? How?

- What guidelines should be considered by social tourism programs that can be both, appealing for the families and maximize the benefits for low-income families?

\section{Methodology \\ Considering the central purpose of the research and the methodologies adopted by previous studies, a mixed methodology was adopted. This methodology integrated quantitative and qualitative analyses, based on secondary and primary data. The empirical study focused upon Portugal.}

The study was structured into three parts. In the first part, the leisure and tourism expenditure patterns of the Portuguese families were analysed, comparing lowincome households with their counterparts, using secondary data. Micro-data were used from the Portuguese Household Budget Survey (PHBS). Bivariate techniques were 
used to compare the low-income households with the other households and Multivariate Regression Analysis was the method used for identifying the determinants of leisure and tourism expenditure.

In the second part, the effects of family tourism and the constraints felt by a sample $(N=1,165)$ of Portuguese families were analysed, using primary data specifically collected for this purpose. Again, univariate and bivariate techniques were used for descriptive and comparative analysis, while multivariate regression analysis and Structural Equations Modelling (SEM) were used for identifying the determinants of leisure and tourism expenditure.

Finally, in the third part, the tourism activity of a sample $(\mathrm{N}=15)$ of low-income families was explored. The data for this component was collected through semi-structured interviews. The individual and collective benefits from tourism were evaluated, as well as the constraints to participate in the tourism activity.

\section{Results}

The results show that family tourism has important effects for individuals and families, and that these effects differ along factors, such as motivations and experiences lived during the tourist practice. Furthermore, results show that the intensity of the effects of tourism varies according to families' socioeconomic characteristics. It was also found that financial constraints are the most important constraint to family tourism for the surveyed families. The analysis culminated in a set of theoretical and practical recommendations and implications regarding the importance of tourism for low-income families. Guidelines for designing or improving social tourism programs for families were identified.

\section{Theoretical conclusions}

The first theoretical contribution results from the construction of a conceptual framework of the relationship between family tourism and fighting social exclusion. The second contribution is related to the fact that research on the family tourism effects is scarce, both for the individual and the family. The literature review involved several scientific fields, such as tourism, sociology, psychology and economics. It is, therefore, a multi-disciplinary study that uses and combines theories and methods from different disciplines.

The empirical study also contributed to the evolution of knowledge in this area, namely: (i) deepens the knowledge of the Portuguese reality regarding the tourism practices and benefits for families; (ii) analyses tourism constraints and how they relate to the economic condition of families; and (iii) analyses the effects of family tourism, its determinants and how these differ according to the economic status of families.

This study enabled the development and validation of quantitative and qualitative methods and techniques that can be adopted for future research on this topic. In methodological terms, another important contribution to consider is the identification of comparable dimensions, which can be replicated and analysed in other empirical investigations.

\section{Practical application of the dissertation}

This research shows that the benefits of family tourism for its participants can be significant and occur in several dimensions. The participation in these programs can change behaviours that are favourable to social exclusion. Hence, the promotion of social tourism initiatives for socially excluded groups, such as the low-income families, could contribute to the social inclusion of these groups, encouraging social cohesion. In line with other authors, we defend that the integration of social tourism programs (STP) in social policies can contribute to increase the efficiency these policies (Hazel, 2005) and even to a possible saving of society's resources (Sousa et al., 2007; Minnaert et al., 2009).

The thesis discusses the challenges for implementing STP. At one level it raises the issue of funding. Indeed, public funded STP are scant. The pressures upon national budgets are immense and will be hasten in the future. There is a systematic unbalance 
between population demands and public resources. Hence, the current social problems require new sources of funding and social innovation initiatives by a variety of actors in the private sphere. Measures to promote these are welcome. At action level it highlights the features that can contribute to the success of STP, in terms of both, maximizing the benefits for families and for society and of offering an appealing experience for families.

\section{Content of the dissertation}

\section{Abstract of chapter one}

The first chapter, the introduction, highlights the relevance of the thesis in the field, presents the objectives, the research questions, the methodology and the structure of the document.

\section{Abstract of chapter two}

Chapter two analyses the importance of the family in society and also as a tourist segment. The effects of tourism for visitors are theoretically explored, as well as the factors that can determine those effects. The chapter ends with a theoretical reflection on tourism constraints.

\section{Abstract of chapter three}

The third chapter explores the relationship between the concepts of social exclusion, low-income families and tourism. The concept of social tourism is discussed and some existing social tourism programs for families are analysed in terms of stakeholders involved, reflecting on the role of tourism in social policy at an international and national level and discussing the benefits these programs can bring to participants.

\section{Abstract of chapter four}

Chapter four is divided into five sections. The first details the research questions. The second section characterizes the empirical context. The following three sections explain the methodologies used for collecting and analysing data.

\section{Abstract of chapter five}

The results of the first part of the empirical study are presented in chapter five. Studies that specifically analyse the tourism and leisure consumption patterns of low-income families and their determinants are rare, and there is a lack of empirical evidence in this area in Portugal. In this context, the tourism and leisure consumption patterns of Portuguese families are analysed. First, a comparison is made between low-income families and other families regarding tourism and leisure expenditure patterns. Secondly, the determinants of tourism and leisure expenditure are identified and, thirdly, it is explored whether there are differences in tourism and leisure expenditure determinants according to the level of the household's income.

\section{Abstract of chapter six}

Chapter six is divided in three parts:

(i) characterization of the sample, families who had at least one family holiday in the last four years and families who did not;

(ii) analysis of the constraints for family tourism, using data collected through a survey to families who did not have a family holiday in the last four years;

(iii) analysis of families' tourism practices, including their motivations, behaviours, experiences and perceptions of the effects of family tourism, using data collected through a survey to families who had family holiday(s) in the last four years.

In all sections a comparison between the surveyed households, based on their Material Deprivation (based on the Material Deprivation rate), is performed.

\section{Abstract of chapter seven}

This chapter begins with the identification of the direct relationship between each type of effect of family tourism and potential determinants through multiple linear regression models. Then a SEM was used to analyse relationships between motivations and experiences lived during the holidays as potential determinants of the tourism effects. It was also considered the potential relationship between motivations, experiences and effects of tourism as determinants of satisfaction and loyalty. Throughout the chapter, groups of families, based on their material deprivation indicators, are compared and the main differences between them are explored. 


\section{Abstract of chapter eight}

Chapter eight focuses upon the tourist practices of a sample of low-income families with children. It is based on data collected with 15 families through semi-structured indepth interviews. The individual and collective benefits arising from tourism participation of these families and the constraints felt to the participation in family tourism are discussed.

\section{Abstract of chapter nine}

The ninth chapter aims to understand the level of participation and interest of families in STP and also to discuss guidelines for these programs so as to maximize their benefits. It is organized into two main sections:

(i) Section 1 analyses the interest and level of participation of families in STP, analysing separately the three segments of families that integrate the global sample analysed families: families who had at least one family holiday in the last four years, families who did not (quantitative approach) and low-income families (qualitative approach);

(ii) Section 2 analyses the results in terms of implications they may have for the definition of STP.

\section{Abstract of chapter ten}

The last chapter presents the main conclusions and implications of the results. In this chapter it is further discussed the importance of the research to the theory and practice. The main limitations of the study and guidelines for future research are also presented.

\section{Main References:}

Gram, M. (2005). Family Holidays. A Qualitative Analysis of Family Holiday Experiences. Scandinavian Journal of Hospitality and Tourism, 5, 2-22.

Haukeland, J. (1990). Non-travellers: the flip side of motivation. Annals of Tourism Research, 17(2), 172-184.

Hazel, N. (2005). Holidays for Children and Families in Need: An Exploration of the Research and Policy Context for Social Tourism in the UK. Children \& Society, 19, 225-236.

Lehto, X.Y., Choi, S., Lin, Y.-C., \& Macdermid, S. M. (2009). Vacation and Family Funtioning. Annals of Tourism Research, 36(3), 459-479.

McCabe, S., Joldersma, T., \& Li, C. X. (2010). Understanding the benefits of Social Tourism: Linking Participation to Subjective Well-being and Quality of Life. International Journal of Tourism Research, 12, 761-773.

Minnaert, L. (2012). Social Tourism as Opportunity for Unplanned Learning and Behavior Change. Journal of Travel Research. Published online version - doi: 10.1177/0047287511431324

Minnaert, L., Maitland, R., \& Miller, G. (2009). Tourism and social policy - The value of social tourism. Annals of Tourism Research. 36(2), 316-334.

Schanzel, H., Yeoman, I., \& Backer, E. (Eds) (2012). Family Tourism: Multidisciplinary Perspectives. Chanel View Publications.

Smith, V., \& Hughes, H. (1999). Disadvantaged families and the meaning of the holiday. International Journal of Tourism Research, 1(3), 123-133.

Sousa, L., Hespanha, P., Rodrigues, S., \& Grilo, P. (2007). Famílias Pobres: Desafios à Intervenção. Lisboa: Climepsi editores. 